\title{
The Association of Nurses Caring Behavior with the Level of Patient Satisfaction, Harari Region, Eastern Ethiopia
}

\author{
Haregeweyn Kibret $\mathbb{D}^{\prime}$, Barkot Tadesse ${ }^{2}$, Adera Debella $\mathbb{D}^{2}$, Meron Degefa ${ }^{2}$, \\ Lemma Demissie Regassa $\mathbb{( D}^{3}$ \\ 'School of Nursing and Midwifery, College of Health and Medical Sciences, Haramaya University, Harar, Ethiopia; ${ }^{2}$ Department of Maternity and \\ Neonatal Nursing, School of Nursing and Midwifery, College of Health and Medical Sciences, Haramaya University, Harar, Ethiopia; ${ }^{3}$ Department of \\ Epidemiology and Biostatistics, School of Public Health, College of Health and Medical Sciences, Haramaya University, Harar, Ethiopia \\ Correspondence: Haregeweyn Kibret, Department of Nursing, School of Nursing and Midwifery, College of Health and Medical Sciences, Haramaya \\ University, P.O. Box, 235, Harar, Ethiopia, Email haregeweynkibret@gmail.com
}

\begin{abstract}
Purpose: The extent to which nurses tailor their care to the patient's specific needs has a direct impact on patient health outcomes. Satisfied people will have good communication with the health professional, which results in good care and health outcome, so this study aimed to assess the association of caring behavior of nurses with the level of patient satisfaction, in public hospitals of the Harari region, Eastern Ethiopia, from March 10 to April 10, 2021.

Methods: A cross-sectional study was conducted among 300 nurses providing inpatient services and 345 randomly selected admitted patients in two public hospitals of Harari region, Eastern Ethiopia. Clinical nurse-patient interaction scale was used to assess the level of caring behavior. The level of patient satisfaction was measured using the patient satisfaction scale tool. We used structural equation modeling to determine the relationship of nurses caring behaviour and the level of patient satisfaction. The association was reported using coefficient $(\beta)$ along with a $95 \%$ confidence interval. The statistical significance of the association was declared at $\mathrm{P}<0.05$.

Results: According to this study, only $51.67 \%$ of the nurses had good caring behavior and $62.90 \%$ of the patients were satisfied with the nursing care they received. The nurses' caring behavior score was increased by $41 \%(\beta=0.41 ; 95 \%$ CI: $0.20,0.63)$ and $(\beta=0.65$; $95 \%$ CI: $0.48,0.81$ ) as nurses' job satisfaction and work environment scores increased by one scale, respectively. Similarly, the score of patient satisfaction was increased by $2 \%(\beta=0.02 ; 95 \%$ CI: $0.01,0.12)$ as the score of nurse caring behaviour was increased by one scale.

Conclusion: Patient satisfaction increased as the nurses care behavior score increased, so nurses must continue to identify ways to evaluate and increase patient happiness, as well as illustrate the impact nurses have on patient satisfaction with hospital experience as a result of their treatment.
\end{abstract}

Keywords: caring, nursing, caring behavior, patient satisfaction

\section{Introduction}

Patient satisfaction is a subjective assessment of a patient's cognitive and emotional response as a result of the interaction between expectations and perceived care. It is defined as the value and reaction of patients to the care they received. As a result, patients evaluate healthcare services and providers from their subjective perspective. ${ }^{1,2}$ There is a strong positive association between patient satisfaction level and healthcare provision indicators. ${ }^{3}$ So assessing patient satisfaction is indirectly assessing the quality of the healthcare system. The feedback given by the patient helps to improve the healthrelated activities.

Patient satisfaction is a multifaceted healthcare construct that is influenced by a variety of factors such as provider characteristics (academic status), quality of care, provision of information and waiting time, nurses' abilities to provide patient-centred care, communication skills, nurses' caring abilities, concern for the patient and competence in diagnosing 
and treating health problem, availability and visibility of nurses, provision of appropriate health-related information in a jargon-free language, nurses' ability to answer questions, and an ability to provide patients with an opportunity to ask questions were factors identified by different studies. ${ }^{4-8}$

Nurses are the most important professional component of "front-line workers" in most health systems, providing up to $80 \%$ of basic healthcare. As a result, they are in a unique position to offer creative and new solutions to present and future global health issues. ${ }^{9}$ Affective support, health information, decisional control, and professional/technical abilities were the attributes that led to the health outcome of patient satisfaction with nursing care. ${ }^{10}$

The extent to which nurses tailor their care to the patient's specific needs has a direct impact on patient health outcomes. Patients were more concerned with the nurse's interpersonal interaction than with her technical abilities. ${ }^{10}$ Satisfied people will have good communication with the health professional, which results in good care and health outcome. On the other direction, if there is no satisfaction, this affects the patient's health and care negatively. Therefore, having the highest level of patient satisfaction with nursing care leads to higher patient adherence to healthcare regimens. ${ }^{11}$ The evaluation of nursing care quality and patient satisfaction allowed for the identification of study area strengths and weaknesses, as well as support for reorganizing care, management, and instructional activities. ${ }^{12}$ Although there are different studies that assess the level of patient satisfaction, there are no studies that assess the association of patient satisfaction with the level of nurses caring behavior specifically in the study area. Therefore, this study aimed to assess the association of nurses caring behavior with the level of patient satisfaction in public hospitals of Harari region, Eastern Ethiopia.

\section{Materials and Methods}

\section{Study Setting, Period, and Design}

The institution-based cross-sectional study was conducted in public Hospitals of the Harari region, which were found in eastern Ethiopia from March 10 to April 10, 2021. Harari region is among the ten regional states found in Ethiopia. According to the Central Statistical Agency (CSA) projection, the region has a total population of 270,031 in 2020. ${ }^{13}$ There are 2 public hospitals (HFSUH and JH), 1 military and 1 private hospitals, 8 health centers ( 4 urban and 4 rural), 19 health posts, and 10 private clinics in the region. Among them, HFSUH and JH provide multidimensional care to patients who need highly qualified/specialized healthcare services. Hiwot Fana Specialized University Hospital (HFSUH) is teaching hospital for Haramaya University with a total of 161 beds and having medical, surgical, gynecology, pediatrics, and psychiatric wards. Jugal Hospital is a regional referral hospital in the Harari region that consists of medical, surgical, and gynecological services with 95 beds. Upto data collection date, there were 240 and 116 nurses serving in the inpatient service of HFSUH and JH, respectively. The two public hospitals (Hiwot Fana Specialized University Referral Hospital and Jugel General Hospital) were selected based on the high patient flow and multidimensional care they provide. Nurses who were on leave during data collection period were excluded. On the other hand, patients who were at the critical data collection period were excluded from the interview.

\section{Population and Eligibility}

Nurses providing inpatient service in public hospitals of Harari region, Eastern Ethiopia, during the data collection period were considered as study population. Nurse professionals serving in the hospital permanently (working in the hospital for more than six months) and serving as an inpatient nurse during the data collection period were included in the study. Patients who were admitted for at least of 1 day in the major inpatient departments of hospitals were included in the study.

\section{Sample Size Determination and Sampling Procedure}

To determine the sample size for this study, outcome variables and various factors significantly associated with the outcome variable were considered. Accordingly, for each specific objective, the sample size is calculated separately and the larger sample size was taken to be used for this study. For the first objective, the magnitude of the high level of nurses' caring behavior $(\mathrm{p}=31.9 \%)$ were obtained from a previous study conducted in Jimma Referral Hospital, 
Southwest Ethiopia hospital. ${ }^{14}$ Hence, the calculated sample size was 334 , the sample size for the second specific objective is determined by considering factors (work experience and personal satisfaction) that are significantly associated with the outcome variable (level of nurses caring behavior), the two-sided confidence level of $95 \%$, the margin of error of 5\%, power of $80 \%$, and the ratio of exposed to unexposed 1:1 using STAT CALC of Epi Info Version 7. Finally, the required sample size for this particular study is decided by taking the maximum from the sample size with a $5 \%$ nonresponse rate, the final sample size was 351 ; however, the total number of nurses providing inpatient services was 300 , so we include all nurses providing inpatient service. All nurses providing inpatient services and 345 randomly selected admitted patients of both public hospitals (Jugal General Hospital and HFSUH) were included after the sample sizes were proportionally allocated accordingly.

\section{Data Collection Methods}

The socio-demographic data questionnaire was developed by reviewing previously published similar articles and other relevant works of the literature. ${ }^{15-17}$ The English version of the CNPI-Nurse scale ${ }^{18}$ was used to determine the level of caring behavior. The CNPI tool contained 23 items with four main dimensions: clinical care, relational care, humanistic care, and comfort care components, and the items were answered on a five-point Likert scale with response options ranging from 1 (Rarely) to 5 (always). The PSS tool contains 10 items with three main dimensions: technical care needs, information care needs, and supportive care needs, and the items were answered with a four-point Likert scale with response options ranging from 1 (very dissatisfied) to 4(very satisfied). ${ }^{19}$ Four BSc nurse data collectors and two MSc supervisors were involved in the data collection process.

We used Cronbach alpha to test the reliability of PSS and CNPI tools; and the score for both PSS and CNPI was 95\% and $94 \%$, respectively.

\section{Study Variables and Definitions}

The level of patient satisfaction (outcome variable) and the level of nurses caring behavior (covariate (independent) variable).

Caring behavior is measured by The Short Scale, which comprises 23 items, reflecting four caring domains: Humanistic Care (four items), Relational Care (seven), Clinical Care (nine), and Comforting Care (three). Then, caring behavior will be classified as high and low based on the median score. ${ }^{18}$ Clinical care is the component of nurses caring behavior that measures clinical skill aspects of nurses with nine items. ${ }^{18}$ Relational care reflects the philosophical aspect of caring that measures the relationship with patients using seven items. ${ }^{18}$ Humanistic care emphasizes the personal worth of the individual, the centrality of values, and the active nature of nurses with their patients. It is measured by four items. ${ }^{18}$ Comforting care: these items are more typical of the unseen job of nursing in terms of patient comfort. It is measured by three items. ${ }^{18}$ Patient satisfaction: The scale consists of 10-items categorized into three dimensions; Technical-scientific careneeds, Information care-needs, and Interaction/support care-needs. All items were scored on a four-point Likert scale $(1=$ very dissatisfied, $2=$ dissatisfied, $3=$ satisfied, $4=$ very satisfied). Then classified as satisfied (if the mean score is above or equal with the median of the mean score) and unsatisfied (below the median of mean score). ${ }^{19}$

\section{Data Quality Control}

English version of self-administered questionnaire was used for nurses while the questionnaire prepared for the patient was translated to the local language and Pretests was conducted on 5\% of the sample size in Haramaya hospital and the necessary corrections were made based on the results of the pretest. The training was given for data collectors and supervisors for 1 day on data collection tools.

A brief introductory orientation was given to the study participants by data collectors about the purposes of the study. The investigators and supervisors monitored the data collection process and check for the completeness and logical consistencies of the collected data and give appropriate feedback accordingly. Intensive supervision was made by supervisors and the principal investigator. 


\section{Data Processing and Analysis}

The collected data was checked for its completeness and cleaned before entry into the computer. Then, the questionnaire was coded and data were entered into Epi data version 3.1 by two data clerks who were recruited. The score of caring behavior of nurses and the patient's satisfaction were calculated using the median and interquartile ranges. The research hypothesis was to determine if the patient satisfaction score was changed with the change of nurse caring behaviour score. This change was modeled by structural equation modeling. The individual and total effect of each nurse's caring behavior was calculated and reported using the regression coefficients $(\beta)$ along with $95 \%$ Confidence interval (CI). The chi-square test was used to measure of fit in SEM because it is a test of statistical significance. The chi-square value and model degrees of freedom were used to calculate a p-value. Nonsignificant result for this test indicates a good model fit. The best fit model was selected using information criteria (AIC and BIC). Model fitness and sensitivity analysis were done by appropriate methods (chi-square or residual fitness). Finally, statistical significance was declared at a p-value $<0.05$.

\section{Ethics Approval and Consent to Participate}

Ethical clearance was obtained from the Institutional Health Research Ethics Review Committee (IHRERC) of Haramaya University College of Health and Medical Sciences (reference number: IHRERC/261/202). Support letters were written to both hospitals in which the study was conducted. Informed, voluntary, written, and signed consent was obtained from the head of each hospital, nurses and participants. Confidentiality was assured for data obtained from the participants through excluding personal identifiers. Additionally, the data was secured with a password, and accessed by investigators only. The protection and procedures for COVID-19 prevention were strictly followed during data collection.

\section{Results}

\section{Socio-Demographic Characteristics of Nurses}

The study included 300 nurses working in the public hospital of the Harari region and the mean ( \pm standard deviation (SD)) age of the nurses was $28.07( \pm 7.09)$ years. Almost half of the respondents $(n=147,49 \%)$ were in the age group $25-$ 34 years. More than half $(n=169,56.33 \%)$ were women, about $(n=141,47 \%)$ of the participants were Orthodox. The majority $(n=239,79.67 \%)$ of the respondents have a BSc in nursing. Regarding the working unit of the respondents $(n=160,53.33 \%)$ was working on the medical ward. Majority $(n=212,70.67 \%)$ of them had 5 years and below work experience (Table 1).

Out of the 351 expected patients, 345 participated in this study making the response rate $98.3 \%$. And the mean $( \pm$ standard deviation) age of the patients was $28.07( \pm 7.09)$ years among the respondents, $214(62 \%)$ were female. More than half $199(57.7 \%)$ of the patients were in the age group between 17 and 30 years. The majority of the respondent 246 $(71.3 \%)$ were rural residents. Regarding marital status, $288(83.5 \%)$ of the patients were married. $147(42.6 \%)$ of the respondents attended primary education. Regarding the admission unit, $141(40.9 \%)$ of the patients were admitted to a medical ward (Table 2).

\section{The Level of Nurses Caring Behavior}

Out of 300 respondents, more than half $(\mathrm{n}=155,51.67 \%)$ of nurses had high overall caring behavior. Among the subscales of caring behaviors, more than half $(\mathrm{n}=155,51.67 \%)$ of nurses had high "clinical care", $(\mathrm{n}=162,54 \%)$ of them had high "relational-care", $(n=177,59 \%)$ of nurses had high "humanistic-care" and $(n=152,50.62 \%)$ of nurses had high "comforting-care" caring behavior (Figure 1).

\section{The Level of Patient Satisfaction}

From the technical-scientific care needs subscale of patient satisfaction, nearly three-fourths, 249(72\%) of them were satisfied with the nurse's overall competency, the majority of them were satisfied with the way nurses approached and treat them and 261 patients (76\%) were pleased with the number of time nurses spent with them. 
Table I Socio-Demographic Characteristics of Nurses Working in Public Hospitals of Harari Region, Eastern Ethiopia

\begin{tabular}{|c|c|c|c|}
\hline Variables & & Frequency & Percent \\
\hline Working hospital & $\begin{array}{l}\text { HFSUH } \\
\text { Jugal hospital }\end{array}$ & $\begin{array}{l}171 \\
129\end{array}$ & $\begin{array}{l}57 \\
43\end{array}$ \\
\hline Age (years) & $\begin{array}{l}\leq 24 \\
25-34 \\
\geq 35\end{array}$ & $\begin{array}{l}109 \\
147 \\
44\end{array}$ & $\begin{array}{l}36.33 \\
49 \\
14.67\end{array}$ \\
\hline Sex & $\begin{array}{l}\text { Female } \\
\text { Male }\end{array}$ & $\begin{array}{l}169 \\
131\end{array}$ & $\begin{array}{l}56.33 \\
43.67\end{array}$ \\
\hline Religion & $\begin{array}{l}\text { Orthodox } \\
\text { Muslim } \\
\text { Protestant } \\
\text { Other }\end{array}$ & $\begin{array}{l}14 \mid \\
120 \\
37 \\
2\end{array}$ & $\begin{array}{l}47 \\
40 \\
12.33 \\
0.67\end{array}$ \\
\hline Marital status & $\begin{array}{l}\text { Married } \\
\text { Single }\end{array}$ & $\begin{array}{l}131 \\
169\end{array}$ & $\begin{array}{l}43.67 \\
56.33\end{array}$ \\
\hline Educational status & $\begin{array}{l}\text { Diploma } \\
\text { BSc } \\
\text { MSc }\end{array}$ & $\begin{array}{l}48 \\
239 \\
13\end{array}$ & $\begin{array}{l}16 \\
79.67 \\
4.33\end{array}$ \\
\hline Working unit & $\begin{array}{l}\text { Medical } \\
\text { Surgical } \\
\text { Pediatrics } \\
\text { Gyne_obse }\end{array}$ & $\begin{array}{l}160 \\
98 \\
26 \\
16\end{array}$ & $\begin{array}{l}53.33 \\
32.67 \\
8.67 \\
5.33\end{array}$ \\
\hline Work experience & $\begin{array}{l}\leq 5 \text { years } \\
\text { Atleast } 6 \text { years }\end{array}$ & $\begin{array}{l}212 \\
88\end{array}$ & $\begin{array}{l}70.67 \\
29.33\end{array}$ \\
\hline
\end{tabular}

From the information care needs subscale majority $272(79 \%)$ of patients were satisfied with the kind of information nurses gave them during hospitalization, majority 271(78.6\%) of patients were satisfied with ways the nurses explained things to them, majority $271(78.6 \%)$ of patients were satisfied with the way nurses prepared them for hospital stay and more than two-third 240(69.6\%) of the patients were satisfied with way nurses prepared them and their family for discharge.

From the interaction/support care needs subscale, the majority, 279(81\%) of patients were satisfied with the overall quality of nursing care they received, majority $274(79 \%)$ of patients were satisfied with the amount of care they received and majority $278(81 \%)$ of patients were happy with their options for specialist nursing care when they required it.

\section{The Association of Nurses Caring Behavior with the Level of Patient Satisfaction}

The final best fitted model containing both structural components (relationship among latent or observable variables) and measurement components (relationships among latent variables (patient satisfaction) and its items) for patients is presented in (Figure 2). The final model was well fitted as chi-square test showed a nonsignificance test result $\left(\mathrm{chi}^{2}=7.9, \mathrm{p}>\mathrm{chi}^{2} \mid 0.058\right)$. Structural equation modeling showed that there is a positive relationship between nurses caring behavior score and patient satisfaction score.

The nurses' caring behavior was increased with the level of nurse's satisfaction $(0.41 ; 95 \%$ CI: $0.20,0.63)$, and working environment ( $\beta=0.65 ; 95 \%$ CI: $0.48,0.81)$. Specifically, the score of nurse caring behavior was increased by 0.41 and 0.65 points as the nurse satisfaction and working environment increased by one score.

The patient satisfaction was increased by 0.01 score as the length of hospital stay $(0.01 ; 95 \%$ CI: $0.00,0.020)$ was increased by one day. Similarly, patient satisfaction was increased by $0.02(0.02 ; 95 \%$ CI: $0.01,0.12)$ score as nurses caring behavior was increased by one score (Table 3). 
Table 2 Socio-Demographic Characteristics of the Patients in Public Hospitals of Harari Region, Eastern Ethiopia

\begin{tabular}{|l|l|l|l|}
\hline Variables & & Frequency & Percent \\
\hline Age (years) & $\leq 16$ & 23 & 6.7 \\
& $17-30$ & 199 & 57.7 \\
& $31-44$ & 55 & 15.9 \\
& $\geq 45$ & 68 & 19.7 \\
\hline \multirow{2}{*}{ Sex } & Female & 214 & 62 \\
& Male & 131 & 38 \\
\hline \multirow{2}{*}{ Residence } & Urban & 99 & 28.7 \\
& Rural & 246 & 71.3 \\
\hline \multirow{2}{*}{ Occupation } & Government employee & 25 & 7.2 \\
& Farmer & 151 & 43.8 \\
& Unemployed & 146 & 42.6 \\
& Private job & 23 & 6.7 \\
\hline \multirow{2}{*}{ Current marital status } & Never married & 47 & 13.6 \\
& Married & 288 & 83.5 \\
& Other & 10 & 2.9 \\
\hline \multirow{2}{*}{ Educational level } & No formal education & 121 & 35.1 \\
& Primary & 147 & 42.6 \\
& Secondary and above & 77 & 22.3 \\
\hline & Medical & 141 & 40.9 \\
& Surgical & 91 & 26.4 \\
& Gyne_obse & 31.8 \\
\hline
\end{tabular}

\section{Discussion}

The quality of service provided by the hospitals can be measured by the level of patients' satisfaction with nursing care. Compared with other health professionals, nursing staff spend the highest time with their patients. Hence, they play a significant role in the overall level of patient satisfaction. ${ }^{20}$

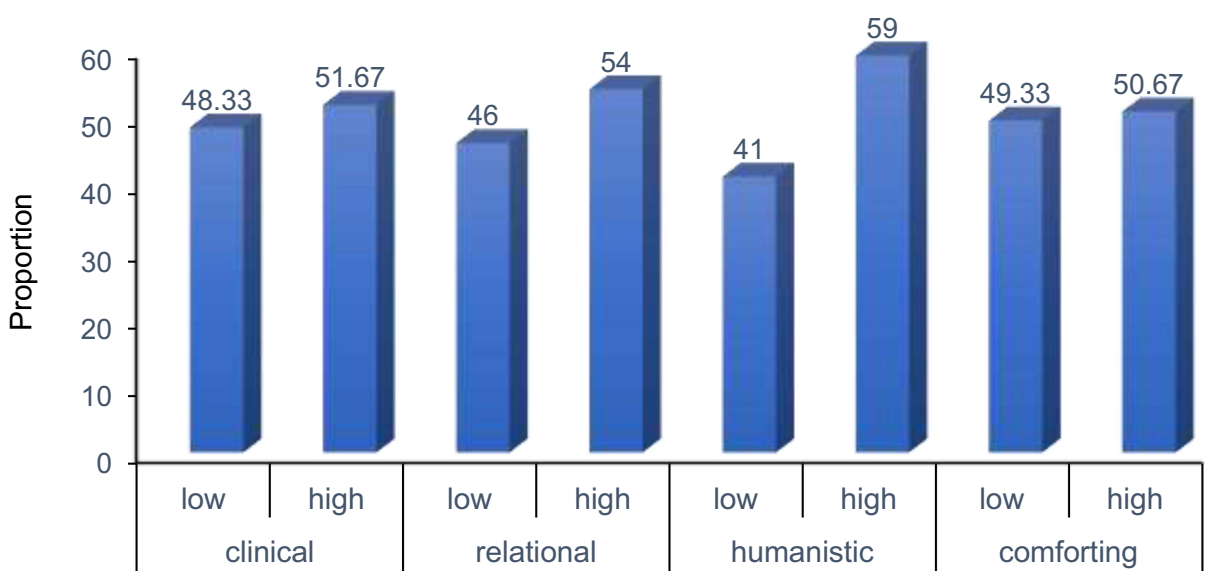

Nurses caring behavior

Figure I Proportion of nurses caring behaviour of participants in public hospitals of Harari region, Eastern Ethiopia. 


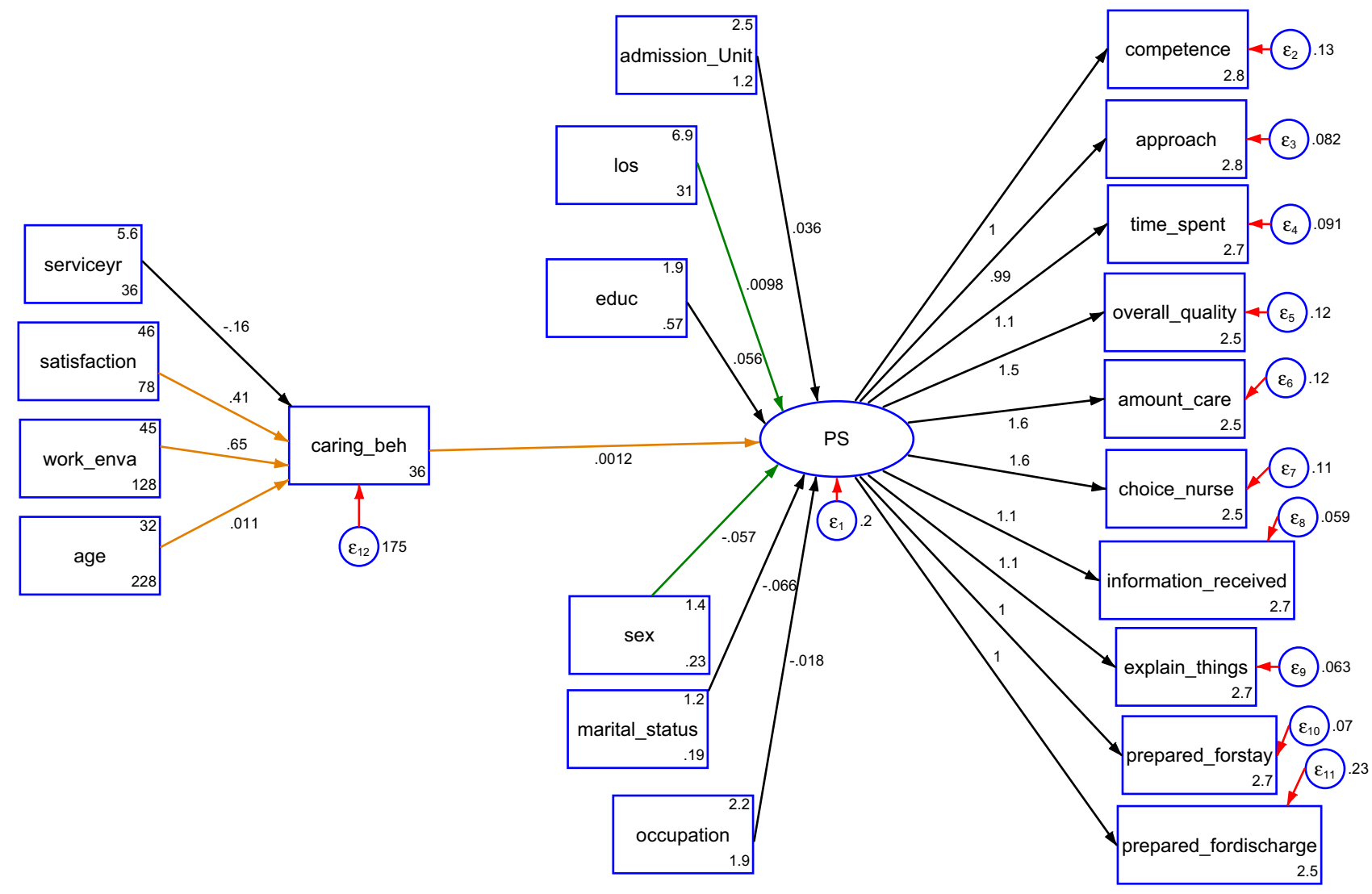

Figure 2 Structural equation model diagram to determine the association of nurses caring behaviour with patients level of satisfaction.

Abbreviations: serviceyr, service year; work_enva, work environment characteristics; caring_beh, caring behaviour; los, length of hospital stay; educ, patients educational level; PS, patient satisfaction.

According to our study, $62.9 \%$ of the patients were satisfied with the nursing care they received. Study conducted in Brazil, ${ }^{21}$ outlined that despite the quality deficit, the patients' satisfaction level with the nursing care received was high. This may be based on the fact that the hospital users belong to a low socioeconomic and education level, ignoring the basic principles of health service quality that need to be complied with and, therefore, expect less from the service and do not know what to require. Studies conducted in Nigeria, Iran, and Saudi Arabia also revealed a high level of patient satisfaction with nursing care $81 \%, 82.8 \%$, and $86 \%$, respectively. ${ }^{22-24}$

This study finding is comparable with study done in truky (63.9\%). The findings also showed that nurses should treat patients with respect, favor, and courtesy by highlighting the value of communication. ${ }^{25}$ The study done in Iraq and Nepal showed that $40.5 \%$ and $49 \%$ of the patients were highly satisfied with the nursing services. This finding is lower than our study result. ${ }^{26,27}$ Most professionals who are faced with congested hospitals, insufficient resources, a shortage of professionals, an excessive work load, and various task demands every day, may not be able to give all nursing care. ${ }^{12}$

This study finding is lower than the study conducted in public hospitals of Mekelle town, the northern part of Ethiopia (79.7\%). ${ }^{28}$ On the other hand, our finding is higher than the study done Addis Ababa reported that $46 \%$ of patient satisfaction. ${ }^{29}$ Our study also presented better patient satisfaction in nursing care than the study conducted in public hospitals of Amhara region, Northwest Ethiopia. ${ }^{20}$ Patients may consider it highly satisfactory as a result of health service access difficulties, users' practice very little their rights to be cared for in public services, placing themselves in a submissive position as if they were receiving a favor and not exercising their right to health. ${ }^{30}$

A consistent proportion of patient satisfaction was determined by nurses' caring behaviors. ${ }^{31}$ All of the nurse's caring conduct must be reviewed, which can be difficult to quantify and explain in terms of effectivity on the patient's end. One of the most important measurements in healthcare is satisfaction. ${ }^{32}$ 
Table 3 Association of Nurses Caring Behavior with the Level of Patient Satisfaction in Public Hospitals of Harari Region, Eastern Ethiopia

\begin{tabular}{|l|l|l|l|}
\hline Variables & Coefficient & $\mathbf{9 5 \%}$ Confidence Interval & P-value \\
\hline Caring behavior & & & \\
\hline Service year & -0.16 & $-0.41-0.10$ & 0.23 \\
\hline Level satisfaction & 0.41 & $0.20-0.63$ & 0.00 \\
\hline Working environment & 0.65 & $0.48-0.81$ & 0.00 \\
\hline Age & 0.01 & $-0.09-0.11$ & 0.84 \\
\hline Patient satisfaction & & & \\
\hline Caring behavior & 0.02 & $0.01-0.12$ & 0.004 \\
\hline Marital status & -0.07 & $-0.19-0.06$ & 0.32 \\
\hline Los & 0.01 & $0.00-0.02$ & 0.05 \\
\hline Sex & -0.06 & $-0.17-0.06$ & 0.34 \\
\hline Occupation & -0.02 & $-0.06-0.02$ & 0.39 \\
\hline Educational level & 0.06 & $-0.01-0.13$ & 0.11 \\
\hline Admission unit & 0.04 & $-0.02-0.09$ & 0.17 \\
\hline
\end{tabular}

Abbreviations: Other, Wakafata; HFSUH, Hiwot Fana Specialized University Hospital; yr, year; Gyne_Obse, Gynecology and obstetrics.

This study finding revealed that there is a positive relationship between nurses caring behavior scores and patient satisfaction scores. As the level of nurses caring behavior is increased by one score the score of patient satisfaction is increased by 0.02 times, this finding is supported by ${ }^{32,33}$ showed that there is a significant positive correlation between caring behavior mean and that of the patient satisfaction. ${ }^{31,34}$ The finding also showed positive relationship between patient satisfaction and nurse caring behavior. Individualised nurse care delivery affects patients' satisfaction with care, suggesting that this quality of care indicator can be used to predict patient satisfaction, one of the outcomes of care. ${ }^{35}$ In contrast, study done in Saudi Arabia outlined that there is no significant correlation between nurses' caring behaviors and patient satisfaction, the study also recommend that the physical setup of hospitals should be a focal point of strategic strategies for continual quality improvement, the study has employed convenience sampling and data were limited to one type of hospital and the finding cannot be generalized beyond that group of patients and nurses. ${ }^{23}$

A systematic review study finding also supports our study finding revealed that nurses' caring ability is one of the factors that affect patient satisfaction. ${ }^{8}$ A study conducted in five European countries also found out a positive correlation between the level of individualized care received and patient satisfaction. ${ }^{35} \mathrm{~A}$ concept analysis by Wagner and Bear and Abera et al, ${ }^{36,37}$ also in line with this study finding,outlined that elements of patient-nurse interaction - effective support, health information, decisional control, and professional-technical competencies - comprise the key attributes of patient satisfaction with nursing care.

\section{Conclusion}

This study finding revealed that patient satisfaction increased as the nurses care behavior score increased, so nurses must continue to identify ways to evaluate and increase patient happiness, as well as illustrate the impact nurses have on patient satisfaction with the hospital experience as a result of their treatment, given the significant emphasis on the outcome of patient satisfaction in today's healthcare market. 


\section{Abbreviations}

CNPI, clinical nurse-patient interaction; COR, crude odds ratio; AOR, adjusted odds ratio; PSS, patient satisfaction scale; HFSUH, Hiwot Fana Specialized University Hospital; IHRERC, Institutional Health Research Ethics Review Committee.

\section{Data Sharing Statement}

The datasets used and/or analyzed during the current study are available from the corresponding author on reasonable request.

\section{Acknowledgment}

We would like to express our heartfelt gratitude to Haramaya University for assisting us with this research.

\section{Author Contributions}

All authors made a significant contribution to the work reported, whether that is in the conception, study design, execution, acquisition of data, analysis and interpretation, or in all these areas; took part in drafting, revising or critically reviewing the article; gave final approval of the version to be published; have agreed on the journal to which the article has been submitted; and agreed to be accountable for all aspects of the work.

\section{Funding}

There is no funding to report.

\section{Disclosure}

All authors declare no conflicts of interest for this work.

\section{References}

1. Ozsoy S, Ozgür G, Akyol A. Patient expectation and satisfaction with nursing care in Turkey: a literature review. Int Nurs Rev. 2007;54:249-255. doi:10.1111/j.1466-7657.2006.00534.x

2. Ammo M, Abu-shaheen A, Kobrosly S, Al-tannir M. Determinants of patient satisfaction at tertiary care centers in Lebanon. Open J Nurs. 2014;04:939-946. doi:10.4236/ojn.2014.413100

3. Xesfingi S, Vozikis A. patient satisfaction with the healthcare system. BMC Health Serv Res. 2016;16(1). doi:10.1186/s12913-016-1327-4

4. Naidu A. Factors affecting patient satisfaction and healthcare quality. Int J Health Care Qual Assur. 2009;22(4):366-381. doi:10.1108/ 09526860910964834

5. Sahin B, Tatar M. Analysis of factors affecting patient satisfaction. Dis Manage Health Outcomes. 2006;14(3):171-183. doi:10.2165/00115677200614030-00006

6. Messina G, Vencia F, Mecheroni S, Dionisi S, Baragatti L, Nante N. Factors affecting patient satisfaction with emergency department care: an Italian rural hospital. Global J Health Sci. 2015;7(4):30.

7. Qureshi MO, Shafqat F, Ahmed S, Niazi TK, Khokhar N. Factors affecting patient satisfaction during endoscopic procedures. Gastrointestinal Endoscopy. 2013;6:7.

8. Rehman SA, Ali PA. A review of factors affecting patient satisfaction with nurse led triage in emergency departments. Int Emerg Nurs. 2016;29:38-44.

9. Hughes F. Nurses at the forefront of innovation. Int Nurs Rev. 2006;53(2):94-101. doi:10.1111/j.1466-7657.2006.00463.x

10. Hsiao HR, Wang PC, Cheng WN, et al. Survey of short-term patient satisfaction after surgery for obstructive sleep apnea. Chang Gung Med J. 2009;32(2):212-219.

11. Wagner D, Bear M. Patient satisfaction with nursing care: a concept analysis within a nursing framework. $J$ Adv Nurs. 2009;65(3):692-701. doi:10.1111/j.1365-2648.2008.04866.x

12. JSd F, AEBdC S, Minamisava R, Bezerra ALQ, Sousa M. Quality of nursing care and satisfaction of patients attended at a teaching hospital. Revista Latino-Americanade Enfermagem. 2014;22:457.

13. CSA. Populations Projections for Ethiopia Addis Ababa, EThiopia; 2013.

14. Oluma A, Abadiga M. Caring behavior and associated factors among nurses working in Jimma University specialized hospital, Oromia, Southwest Ethiopia, 2019. BMC Nurs. 2020;19(1):19. doi:10.1186/s12912-020-0407-2

15. Vandenhouten C, Sylvia Kubsch P, Peterson RN, Lehrer JML. Factors Impacting Nurses Professional Caring. Lippincott Williams \& Wilkins; 2012.

16. Youssef HAM, Mansour MAM, Ayasreh IRA, Mawajdeh NAAA. A medical-surgical nurse's perceptions of caring behaviors among hospitals in Taif City. Life Sci J. 2013;10:4.

17. Ashenafie T, Tebeje N, Gardew D, Gebrie M. perception of caring behaviours and associated factors among nurses. Asian Pac J Nurs. 2015;2 (1):17-24. 
18. Cossette S, Cote JK, Pepin J, Ricard N, D'Aoust L-X. A dimensional structure of nurse-patient interactions from a caring perspective: refinement of the Caring Nurse-Patient Interaction Scale (CNPI-Short Scale). Caring Nurse-Patient Interactions. 2006;55(2):198.

19. Suhonen R, Välimäki M, Leino-Kilpi H, Kim HS. The Patient Satisfaction Scale - An empirical investigation into the Finnish adaptation. $J$ Eval Clin Pract. 2006;13(1):31.

20. Kasa AS, Gedamu H. Predictors of adult patient satisfaction with nursing care in public hospitals of Amhara region, Northwest Ethiopia. $B M C$ Health Serv Res. 2019;19(1):52.

21. Freitas J, Silva A, Minamisava R, Bezerra ALQ, Sousa M. Quality of nursing care and satisfaction of patients attended at a teaching hospital. Rev Lat Am Enfermagem. 2014;22:454-460. doi:10.1590/0104-1169.3241.2437

22. Akhtari-Zavare M, Abdullah MY, Hassan STS, Said SB, Kamali M. Patient satisfaction: evaluating nursing care for patients hospitalized with cancer in Tehran teaching hospitals, Iran. Glob J Health Sci. 2010;2(1):117. doi:10.5539/gjhs.v2n1p117

23. Atallah MA, Hamdan-Mansour AM, Al-Sayed MM, Aboshaiqah AE. Patients' satisfaction with the quality of nursing care provided: the Saudi experience. Int J Nurs Pract. 2013;19(6):584-590. doi:10.1111/ijn.12102

24. Mobolaji-Olajide OM, Adereti SC, Odutayo PO, Adejumo PO. In-patient satisfaction with nursing care: outcome measurement in a tertiary health facility in Lagos, Nigeria. Int J Afr Nurs Sci. 2020;13:100264.

25. Karaca A, Durna Z. Patient Satisfaction with the Quality of Nursing Care. WILEY NursingOpen; 2018.

26. Al-Tawil NG, Mustafa I, Ismahil Z. Inpatients' satisfaction toward nursing services in the medical and surgical wards of Rizgary Teaching Hospital, Erbil, Iraq. Zanco J Med Sci. 2016;20(1349-55).

27. Thapa S, Joshi A, editors. Patient" Satisfaction with Quality Nursing Care At Teaching Hospital. Chitwan; 2019

28. Marama T, Bayu H, Merga M, Binu W. Patient satisfaction and associated factors among clients admitted to obstetrics and gynecology wards of public hospitals in Mekelle town, Ethiopia: an Institution-based cross-sectional study. Obstet Gynecol Int. 2018;2018:1.

29. Asamrew N, Endris AA, Tadesse M. Level of patient satisfaction with inpatient services and its determinants: a study of a specialized hospital in Ethiopia. J Environ Public Health. 2020;2020:2473469. doi:10.1155/2020/2473469

30. de Paiva SMA, Gomes E-A. Hospital care: assessment of users' satisfaction during hospital stay. Revista Latino-Americana de Enfermagem. 2007;15(5):973-979.

31. Palese A, Tomietto M, Suhonen R, et al. Surgical patient satisfaction as an outcome of nurses' caring behaviors: a descriptive and correlational study in six European Countries. J Nurs Scholarship. 2011;43(4):341-350. doi:10.1111/j.1547-5069.2011.01413.x

32. MAN KACC, Soriano GP. Caring behavior and patient satisfaction: merging for satisfaction. Int J Caring Sci. 2018;11:697.

33. Azizi-Fini I, Mousavi M-S, Mazroui-Sabdani A, Adib-Hajbaghery M. Correlation between nurses' caring behaviors and patients' satisfaction. Nurs Midwifery Stud. 2012;1(1):36-40. doi:10.5812/nms.7901

34. Larrabee JH, Ostrow CL, Withrow ML, Janney MA, Jr GRH, Burant C. Predictors of Patient Satisfaction with Inpatient Hospital Nursing Care. Wiley InterScience; 2004.

35. Suhonen R, Papastavrou E, Georgios EG, et al. Patient satisfaction as an outcome of individualised nursing care. Scand J Caring Sci. 2011;26 (2):372.

36. Wagner D, Bear M. Patient satisfaction with nursing care: a concept analysis within a nursing framework. J Adv Nurs. 2008;65(3):692.

37. Abera RG, Abota BA, Legese MH, Negesso AE. Patient satisfaction with clinical laboratory services at Tikur Anbessa Specialized Hospital, Addis Ababa, Ethiopia. Patient Prefer Adherence. 2017;11:1181-1188. doi:10.2147/PPA.S132397

Nursing: Research and Reviews

\section{Publish your work in this journal}

Nursing: Research and Reviews is an international, peer-reviewed, open access journal publishing original research, reports, reviews and commentaries on all aspects of nursing and patient care. These include patient education and counseling, ethics, management and organizational issues, diagnostics and prescribing, health outcomes, economics and resource management, improving patient safety in all settings. The manuscript management system is completely online and includes a very quick and fair peer-review system. Visit http://www.dovepress.com/ testimonials.php to read real quotes from published authors.

Submit your manuscript here: http://www.dovepress.com/nursing-research-and-reviews-journal 